\title{
Noticias sobre violencia en los periódicos regiomontanos, durante 2010
}

\author{
Sergio Manuel de La Fuente VaLdeZ \\ Universidad Autónoma de Nuevo León \\ rayserman@hotmail.com \\ Lucinda SEPÚlVEDA GARCÍA \\ Universidad Autónoma de Nuevo León \\ ly.sepulveda@hotmail.com
}

\begin{abstract}
Resumen:
Investigación que analiza las noticias sobre seguridad pública en N. L. durante 2010, en los diarios El Norte, El Porvenir y Milenio, para determinar la violencia y sus modalidades en las noticias, conocer espacios y características de los titulares, determinar la clasificación de hechos, actores principales, secundarios y lenguaje. Espacios variados y contrastantes. Los encabezados oscilan entre 6 y 8 palabras. Hechos: accidentes de tránsito, asesinatos, secuestros, levantones, manifestaciones, robos, liberaciones y ejecuciones. La violencia se presenta en todos sus tipos.
\end{abstract}

Palabras clave: noticias; seguridad pública; nota roja; violencia; inseguridad; actores; hechos.

\section{News about violence in Monterrey newspapers, during 2010}

\begin{abstract}
:
Research that analyzes the news on public security in N. L. during 2010, newspapers El Norte, El Porvenir and Milenio, to determine the violence and its forms in the news learn about spaces and characteristics of holders, determine the classification of facts, actors main, secondary and language. Varied and contrasting spaces. The headlines ranged from 6 and 8 words. Facts: accidents in transit, murders, abductions, accidents, demonstrations, theft, release and executions. The violence is presented in all its types.
\end{abstract}

Key Words: news, public safety, sensationalist, violence, insecurity, actors, facts.

\section{Referencia normalizada:}

De la Fuente Valdez, S. M. y Sepúlveda García, L. (2014): Noticias sobre violencia en los periódicos regiomontanos, durante 2010. Historia y Comunicación Social. Vol. 19. Núm. Especial Marzo. Págs. 255-264.

Sumario: 1.- Introducción; 2.-Proyecto de Investigación; 3.-Metodología de Investigación; 4.- Consideraciones teóricas y noticias; 5. La Nota Roja; 6.-Hechos o acontecimientos manifestados en los titulares;7 Resultados; 8. Conclusiones. 


\section{Introducción}

La nota roja, conocida también como seguridad pública ,constituye uno de los tipos de noticias más leído por los públicos mexicanos de las diferentes clases sociales, donde está presente por lo general el amarillismo o sensacionalismo en las publicaciones de hechos delictivos en todas sus variantes, que acontecen en las ciudades mexicanas y Monterrey no es la excepción. Aunado a todo ello, en Monterrey y los municipios de la zona conurbada y otras regiones del Estado de Nuevo León se han visto afectados por la presencia y acciones de los grupos de la delincuencia organizada y una constante guerra entre las diferentes bandas que controlan el mercado de las drogas al mayoreo y menudeo, siendo las noticias relacionadas con ello una constante.

\section{Proyectos de investigación}

La sección de seguridad pública es una de las más importantes en los diarios mexicanos. Los hechos publicados en esta parte del diario conllevan la violencia que abarca toda su tipología. A través de los últimos ocho años, en el Estado de Nuevo León, principalmente en la zona metropolitana de Monterrey, su capital, en área citrícola, así como el norte y noreste de la entidad se ha incrementado considerablemente la violencia, manifestada a través de diferentes acontecimientos: robos, homicidios, riñas, pero sobre todo la violencia relacionada con las actividades delictivas realizadas por las organizaciones criminales que operan en nuestro estado (secuestros, torturas, ejecuciones en diversas modalidades, granadazos, principalmente.

Esta investigación servirá para dar cuenta a la opinión pública, a las autoridades municipales, estatales y federales del índice de inseguridad en que vivimos los habitantes de la zona metropolitana de Monterrey y los nuevoleoneses, en general, ante el aumento constante de la ola de violencia que azota a nuestro estado. Asimismo, a los directivos y dueños de los periódicos locales para la reflexión necesaria con su respectiva toma de decisiones al respecto y a las autoridades de la Procuraduría General de la República (PGR), en Nuevo León.

\subsection{Objetivos específicos}

Determinar los espacios que ocupan las noticias que abordan el tema de la seguridad pública, con énfasis en la violencia en Nuevo León y la cantidad de publicaciones. Conocer los principales hechos que alteran la seguridad pública en Nuevo León. Establecer los tipos o clases de violencia como parte de la seguridad pública en Nuevo León. Determinar los actores principales y secundarios de los hechos. Conocer la tipología del lenguaje y su tratamiento. Hubo limitaciones de recursos humanos y de tiempo. 


\section{Metodología de investigación}

- 3.1.-Confiabilidad y validez: Se elaboró un manual de contenido con categorías y subcategorías, donde se incluyen con varios ítems cada una de las variables. Se revisó que cada una de ellas fuera medida y considerada en el manual, en el mismo orden de éstas.

- 3.2.-Conceptualización y operacionalización de variables: Se definió cada una de las variables consideras y se hizo una relación de cada variable con las preguntas o ítems enumerados en el manual de contenido, de manera que todos los números y preguntas estuvieran relacionados con una de las variables.

- 3.3.-Registro de Datos: Se elaboró una ficha técnica con los mismos datos, donde se registró cada uno de los elementos incluidos en el análisis de contenido de los mensajes de las noticias consideradas como discursos periodísticos.

\section{Consideraciones teóricas y noticias}

La noticia como género periodístico informativo y a la vez el más objetivo, ha sido definida y estudiada ampliamente por ser base y fundamento del resto de los demás géneros periodísticos, en sus clasificaciones (informativos, de opinión, interpretativos y mixtos o híbridos).

La notica es considerada como el relato de hechos o acontecimientos actuales de interés público para una sociedad, que sigue todo un proceso, el cual incluye la recopilación de la información y su adecuación, con la participación de los guardabarreras o gatekeeper, la selección de ellas y, finalmente, su publicación en los periódicos impresos o digitales para ser leídas por un público a quien le llega como tercera o cuarta realidad de los hechos, luego de las transformaciones que tuvo el mensaje, durante el proceso y aparezca como producto terminado.

(Gomis, en Esquivel, 2009) considera que el periodismo es un método de interpretación de la realidad social, que puede ser captada en la medida que se percibe, fragmentada por unidades independientes y completas, denominadas hechos. La noticia es la expresión periodística de un hecho, capaz de interesar hasta el punto de suscitar comentarios; un hecho que dará de qué hablar.

La noticia puede entenderse como nueva información o artículo nuevo y tiene tres alcances básicos: nueva información sobre sucesos, objetos o personas, como un programa (radio o TV), en el cual se presentan informaciones periodísticas. También como un informe periodístico. Un texto en un diario o un relato en radio, televisión o la internet, en el cual se ofrece una nueva información sobre sucesos recientes (Clauso, 2007). 
En las actuales sociedades de la información, resulta difícil pensar en los alarmismos sociales sin contemplar el papel de los medios. Las industrias de la comunicación aparecen como los grandes mediadores entre la ciudadanía y el mundo del delito. Buena parte de lo que los individuos saben y se imaginan del crimen tiene que ver con las imágenes difundidas en la televisión, las informaciones radiofónicas y los discursos en la prensa escrita. (Barata, 2010, a).

Los medios de comunicación masiva son el vehículo mediante el cual los periodistas ejercen su influencia. La utilización de éstos sin el conocimiento de sus alcances y su importancia en la vida de las personas resulta negativa. Un mal manejo de la información, puede contribuir al desarrollo de prejuicios sociales, etnocentrismo al juzgar los acontecimientos, según el entorno en el que se vive: expresar dogmatismo, expresar ideas rígidas de pensamiento, subjetividad e impresionismo (Gorz y Urrolla, 1988).

El combate entre hombres, sea entre ejércitos, ideologías o el de poderes, siempre ha intrigado a las multitudes. En las noticias de tono violento: guerras, incendios, motines, tiroteos y disturbios, el factor conflictivo es fundamental. Todos los periodistas saben que cualquier lucha por una supremacía constituye un elemento de interés periodístico (Warren, 1975).

\section{La nota roja}

El subgénero de la nota roja forma parte de ese proceso comunicacional, combinando en sus relatos, motivaciones lingüísticas y sociológicas. Este subgénero se hace cargo de los hechos apartados de la normalidad cotidiana, por intermediación de algún tipo de violencia. Sus protagonistas, lugares y desenlaces, recrean en las líneas, múltiples articulaciones de la práctica social.

La nota roja solo evoca una parte de los conflictos sociales que nos hacen sufrir y llenan de inseguridades. En las piezas de los noticieros, en las páginas de los diarios aparecen predominante, aquellos hechos violentos que entran en conflicto con la ley penal, aquellos acontecimientos en los que interviene la policía o el juez (Barata, b). Estas informaciones generan un estado de incertidumbre en el ciudadano que a diario se enfrenta con la lectura de este tipo de noticias, las cuales, en algunos casos son magnificadas por los medios, a través de los textos y la profusión de fotografías escabrosas (Cerbino, en Aguillón, 2010).

La nota roja nos relata la sangre derramada de las tragedias y de los dramas humanos pero sólo los referidos a las inseguridades penales. Los discursos mediáticos olvidan frecuentemente las inseguridades sociales que padece buena parte de la población. El sufrimiento no siempre está donde creemos. Hay un dolor que se expresa en gritos y otros en que se sufre calladamente, con resignación e injusticia (Barata, c). 
Los personajes que protagonizan esta clase de eventos difícilmente serán recordados ni se sabrá más de ellos, pues sólo buscan mostrar aspectos de la condición humana: la malicia o lo inevitable y trágico de determinados fenómenos naturales. La forma en que se presenta tiene la función de complementar esa realidad que los medios ofrecen a sus lectores (Arriaga, 2002).

La prensa amarilla ha evolucionado, de las primeras planas del Journal de New York, de 1895, pasando por el Bild alemán. El sensacionalismo ha permeado, tanto a la prensa seria, como a la televisión y a la radio. A diferencia de la prensa amarilla de finales del siglo XIX, en nuestro medio, esta prensa se ocupa muy poco de las noticias internacionales o de personajes de la realeza. Más bien aparece una lista interminable de personas anónimas, como albañiles, obreros, profesores, vendedores ambulantes, entre otros (Macassi, 2006).

El periodista Fraga expresa que en un principio, la nota roja estaba confinada a las partes interiores de los diarios, en la famosa sección policiaca y prácticamente inexistente en los noticieros de radio y televisión. No fue hasta principios de los noventa, cuando fueron asaltados los encabezados de las primeras planas de la prensa y los principales espacios noticiosos y de opinión de la radio y la televisión mexicanas, convirtiéndose en la principal preocupación para millones de personas(Guerrero,2010). A mediados de los noventa se acentuó más la presencia de los narcos en la zona norte del país. No era una situación nueva, pero ya se hacía evidente el amplio espectro que ocupaba el mundo de los narcotraficantes (Rodríguez, 2007).

La violencia cobra cada vez más peso en la programación de las estaciones de radio y la televisión, en la prensa y la Internet, lo cual, a su vez, tiene más influencia en la existencia y percepción de la misma. En general, vivimos en sociedades altamente mediatizadas, al extremo que la frase acuñada "lo que no está en los medios, no existe", se ha convertido en una realidad (Carrión, 2008).

Los estándares de vida que exhibe la cultura mediática son los mismos que rigen en la vida cotidiana: conflictos de pareja, dramas familiares, droga, problemas de la edad, de inseguridad, de violencia; las figuras del imaginario industrial no proponen nada absolutamente nuevo (Lipovetzky 1987:253).

El sensacionalismo en la noticia sobre el crimen se expresa en titulares que apelan a la permanente impunidad del crimen y a la imposibilidad de reducirla. Estas noticias provocan, para Cerbino (ibídem: 95), una sensación de omnipresencia del crimen que justifica el alarmismo. La alta promoción mediática de la inseguridad profundiza la desconfianza y el desapego de la población a las instituciones responsables de protegerla. En el sensacionalismo intervienen dos recursos importantes como son la dramatización y la creación de una supuesta realidad.

No obstante, en ocasiones, las empresas mediáticas privilegian sus objetivos de maximización de la ganancia antes que invertir en la capacitación de" los profesionales, y así elevar la calidad informativa. Estas prácticas vienen a ocasionar diferencias en el manejo de información, dándole mayor énfasis a aquellos delitos cometidos por las personas provenientes de las clases sociales vulnerables, que a aquellos los 
hechos o los sucesos protagonizados por las clases altas de la sociedad (Ragagnin, 2007). La utilización responsable de las fuentes informativas es parte fundamental del periodismo.

\section{Hechos o acontecimientos manifestados en los titulares}

\subsection{Primer Período (enero, febrero, marzo y abril de 2010).}

Algunos hechos publicados en el Periódico El Norte: Roban vehículo a 3 conductores. Intenta asaltar farmacia con pistola descompuesta. Asesina a su esposo de tiro en la nuca. Mueren 3 jóvenes en persecución. Era guardia el ejecutado en Pesquería. Rescata el ejército a un secuestrado.

Algunos hechos publicados en El Porvenir, en la sección local: Lo detienen a balazos. Intenta escapar y es detenido. Golpean a vendedor ambulante. Zafarrancho en congreso por nuevo estadio. Intenta anciano herir a policías. Pelean mujeres. Asesina mujer a su esposo. Libera militar a secuestrado.

Algunos hechos publicados en el diario Milenio. Secciones Metrópoli y Ministerio Público: Suspenden a uniformados por desconocer qué es una colostomía. Se enfrentan militares a sicarios en Parás. Explota bomba casera en Cadereyta Jiménez. Frustran un asalto en casa de cambio. Le dan 8 balazos y sobrevive. Va por hamburguesa y recibe un disparo.

Hechos: suspensión de uniformados, detención de policías por cómplices, violencia por construcción de estadio rayado, enfrentamiento entre militares y sicarios, chocan y se matan, mujer asesina a marido, riña campal en vía pública, agresión a mujeres, explosión de bomba casera, ejecuciones, levantón en escuela secundaria, detención de falsos zetas.

6.2 Segundo Período (mayo, junio, julio y agosto de 2010)

Algunos hechos publicados en el diario El Norte, en la sección de seguridad: Militares detienen una camioneta, tras un enfrentamiento con personas armadas. Enfrentamiento entre el Ejército Mexicano e integrantes del Cártel de los Beltrán Leyva.

Algunos hechos publicados en el diario El Porvenir, en la sección local: Unos sujetos a bordo de una camioneta empezaron a disparar contra un vehículo estacionado. El matrimonio escapó luego de ser acusado por vecinos del maltrato que sufrió la menor, al estar encerrada.

Algunos hechos publicados en el diario Milenio, en las secciones Metrópoli y Ministerio Público: 
Elementos del ejército mexicano repelieron la agresión de parte de un grupo de la delincuencia organizada, decomisando armas, autos y liberando a una persona secuestrada.

\subsection{Tercer Período o etapa (septiembre, octubre, noviembre y diciembre)}

Periódico El Norte; Quema crimen a IP de Juárez. Lanzan granadas a juzgados y penal. Ignoran orden, ejército dispara y muere menor. Se triplica el robo violento de vehículos en este año.

Diario Milenio: Lo asesinan de dos tiros dentro de cafetería. Comando asesina y rafaguea a un joven. Los zetas diluían en ácido a sus víctimas. Otra Víctima inocente.

Diario El Porvenir: Matan a 4 policías en Juárez. Llevan a ocho sicarios al CERESO de Apodaca. Visita a su novia y lo matan. Relacionan a roba tráileres con secuestros.

Notas relacionadas en los tres periódicos y los 3 períodos o etapas: como los días analizados en los tres periódicos son los mismos, varios hechos se repiten en dos periódicos pero con diferentes titulares: el caso de la mujer que asesinó a su esposo, el esposo que asesinó a su mujer y a su niña, el luchador que asesinó a su amigo. Otras noticias repetidas en los tres periódicos son: las manifestaciones en el Congreso del Estado por la construcción del Estadio de Fútbol de los Rayados de Monterrey, la liberación de secuestrados, el dueño que asustó a los ladrones y huyeron. Varias ejecuciones, secuestros, asaltos a taxistas, entre otros.

\subsection{Tipología o modalidad de la violencia.}

En los hechos, sucesos o acontecimientos publicados en los 3 periódicos objeto de estudio y en las 3 etapas o períodos se presentan todas las modalidades en que se manifiesta la violencia: verbal, física, psicológica y familiar, en sus diferentes niveles. Por lo general, van unidas la violencia física y psicológica. En todas las noticias se percibe la amalgama de conductas negativas y quizá enfermizas de los seres humanos y se utilizan muchos instrumentos para llevar a efecto las agresiones, en donde en un significativo porcentaje, se terminó con el asesinato de las personas, en diferentes formas. Este cúmulo de hechos delictivos dados a conocer en las noticias en los diarios regiomontanos estudiados, es una muestra fehaciente de la inseguridad que existe en Monterrey y su área metropolitana, así como en otros municipios semiurbanos y rurales del Estado de Nuevo León y del norte y centro de nuestro país.

\subsection{Actores o personajes, protagonistas de los hechos publicados en las noticias.}

En los tres diarios y en los tres períodos o etapas del estudio, en su mayoría son personajes primarios, en muy casos son secundarios.

Militares, hombres armados, bomberos, integrantes del cartel de los Beltrán Leyva, de los Zetas, del Cártel del Golfo, delincuente alias la piña, jefe de grupo de la policía ministerial, investigadores, elementos del ejército mexicano, pandilleros, menor 
baleado, vecinos inconformes, hombre ejecutado, agentes policiacos, AEI, jóvenes con armas de fuego, un ladrón, Elementos del grupo de reacción inmediata, elementos de la marina, "halcones", policía ministerial, policías de Seguridad Pública del Estado, personal de la Cruz Roja y Cruz Verde metropolitana, personal del DIF, niños maltratados, taxistas asaltados, ,ex guardia de seguridad, integrantes de la delincuencia organizada.

6.6. Lenguaje empleado en la publicación de las noticias y su tratamiento, en los 3 periódicos y en las 3 etapas.

El lenguaje empleado en la redacción de los discursos periodísticos, en su modalidad de noticia en el Periódico El Norte es entendible para los diferentes públicos, accesible, coloquial, con riqueza de vocabulario. Los encabezados de las noticias tienen de 5 a 7 palabras. Una de ellas siempre es un verbo, en pocas ocasiones son dos y con él o ellos se inicia por lo general el titular de la noticia, lo acompañan sustantivos y adjetivos con suficiente carga lingüística.

En la redacción de la noticia se utilizan muchos verbos, sustantivos comunes y propios, abundantes adjetivos y adverbios. Los párrafos son muy cortos, entre $3 \mathrm{y}$ 5 renglones, razón por la cual hay en promedio de 10 a 12 párrafos, en todas las noticias publicadas en este medio.

El lenguaje utilizado en los titulares y la redacción de las noticias publicadas en El Porvenir es sencillo, entendible, de uso cotidiano, sin rebuscamientos. Los nombres de muchos de los delincuentes tienen su respectivo alias. Los encabezados de las noticias son de regular extensión, de 5 a 6 palabras. Siempre llevan un verbo conjugado con el que se inician. En escasos titulares emplean dos verbos. Las noticias ocupan entre 6 y 8 párrafos, los cuales son más cortos que en Milenio y más extensos que en El Norte.

\section{7.-En el periódico Milenio.}

El lenguaje empleado por los redactores de las noticias es más coloquial. Emplea vocablos más populares, en muchos casos con autorregulación lingüística. Los titulares tienen entre 6 y 8 palabras. Al igual que en los restantes diarios, empiezan casi todos con un verbo. Hay casos en que tienen hasta dos verbos. Llevan también adjetivos, sustantivos y adverbios. En la redacción del texto se emplean muchos y variados verbos, adjetivos en sus diversas clasificaciones, principalmente calificativos que ayudan a matizar las expresiones, sustantivos comunes y propios. Éstos últimos en nombres de personas, instituciones, organismos de bienestar social, así como abundantes adverbios, Frecuentemente, en los nombres de los delincuentes se registran los alias, que se ha vuelto de uso cotidiano en las clases socialmente medias y bajas y últimamente se ha acentuado en la delincuencia organizada. 


\section{Resultados}

Los espacios ocupados por la publicación de las noticias en los diarios objeto de estudio son muy variados: las páginas del Periódico El Norte miden 57.8 x $31.8 \mathrm{~cm}$. Las noticias van desde $15.6 \mathrm{~cm}$ x $11 \mathrm{~cm}$, pasando por $23.9 \mathrm{~cm}$. $19.7 \mathrm{~cm}$, hasta 19.8 x $31.6 \mathrm{~cm}$. En promedio tienen entre 18.2 y $22.3 \mathrm{~cm}$. El porcentaje ocupado por la publicación de las noticias, en relación con el total de la página oscila desde el $6.4 \%$, hasta el $30.2 \%$. En promedio, es el $20.5 \%$, incluyen texto y fotografías.

En el Periódico El Porvenir, la página mide $58 \mathrm{~cm} \times 32 \mathrm{~cm}$. Los espacios ocupados por las noticias van desde $11.5 \mathrm{~cm}$ x $8 \mathrm{~cm}$, pasando por $13.6 \mathrm{~cm}$ x $5 \mathrm{~cm}$, hasta 25.2 $\mathrm{cm} \times 22 \mathrm{~cm}$. En promedio tienen alrededor de $18.5 \mathrm{~cm} \times 15.4 \mathrm{~cm}$. El porcentaje en promedio de los espacios ocupados en relación con el total de la página oscila en el $14.2 \%$.

En el Periódico Milenio, las páginas miden $28.7 \mathrm{~cm}$ x 41.02 . El espacio ocupado por las noticias oscila entre los $5.3 \mathrm{~cm} \times 7.6 \mathrm{~cm}$, pasando por $17.8 \mathrm{~cm} \times 10.2 \mathrm{~cm}$, hasta $25.9 \mathrm{~cm} \times 20.1 \mathrm{~cm}$. En promedio tienen $18.4 \mathrm{~cm}$ x $14.8 \mathrm{~cm}$. El espacio ocupado por las noticias, en relación con el total de la página, va desde el 3.2\%, pasando por el $8.2 \%$, el $16.6 \%$, el $22.3 \%$, hasta el $44.2 \%$. En promedio oscila entre el $26.8 \%$.

Los espacios ocupados por las noticias en los tres diarios objeto de estudio, en promedio en las tres etapas son muy variados y hasta extremosos. Quien dedica más espacios a las noticias en lo general es el Periódico El Norte. La tipografía empleada en los 3 periódicos es muy diferente y variada en sus caracteres.

\section{Conclusiones}

8.1 La noticia ha sido considerada desde distintas perspectivas: como nueva información, como primera información de un hecho. Es el suceso o hecho público, la materia prima del periodismo. La noticia es un escrito veraz, oportuno, objetivo. Es la expresión periodística de un hecho, capaz de interesar hasta suscitar comentarios y provocar de qué hablar. Es todo suceso trascendente que interesa a la mayoría y transmite la realidad periodística, sin mentir ni deformar los acontecimientos.

8.2. Las noticias son las afirmaciones o negaciones de un hecho. Pueden ser oficiales, extraoficiales, de observación directa y de ambiente. Deben reflejar el hecho o acontecimiento sucedido, a través del cuándo, dónde, cómo, por qué sucedió y en qué circunstancias. Sus principales valores o factores de interés son: actualidad, trascendencia, magnitud, prominencia, proximidad física y psicológica, expectación, rareza, progreso y hazaña.

8.3. La nota es similar a la noticia pero responde a menos elementos, por eso es más corta. La nota roja es considerada como una especie de subgénero, en el proceso comunicativo que combina motivaciones lingüísticas y sociológicas, con variados 
protagonistas, en múltiples lugares, con infinidad de articulaciones en la práctica social.

8.4. La nota roja relata todo aquello que produce dolor o pena y se manifiesta en muchas conductas negativas en la existencia de las personas. En ella los protagonistas o personas involucradas tienen a caer en el anonimato, ya que su participación no es lo relevante, lo que importa es el hecho consumado

8.5. Las medidas del periódico El Norte son: $57.8 \mathrm{~cm} \times 31.8 \mathrm{~cm}$. Las de los espacios son muy variadas y llegan hasta el extremo, de $15.6 \mathrm{~cm} \mathrm{x} 11 \mathrm{~cm}$., hasta $19.8 \mathrm{~cm} \mathrm{x}$ $31.6 \mathrm{~cm}$. El $17.8 \%$ de la publicación, en relación a la página.

Las páginas de El Porvenir miden $58 \mathrm{~cm}$ x $32 \mathrm{~cm}$. Son más variados los tamaños de los espacios ocupados por las noticias, van desde $11.8 \mathrm{~cm}$ x $8.5 \mathrm{~cm}$, hasta $26.2 \mathrm{~cm} \mathrm{x}$ $22.5 \mathrm{~cm}$. El porcentaje de la publicación de la noticia, en relación con el total de la página, es del $15.3 \%$.

8.6. En el diario Milenio, la medida de la página es de $28.7 \mathrm{~cm} \times 41 \mathrm{~cm}$. Los espacios ocupados por las noticias, oscilan entre los $5.6 \mathrm{~cm} \times 7.9 \mathrm{~cm}$, hasta los $25.7 \mathrm{~cm}$ x $20.5 \mathrm{~cm}$. En promedio, el porcentaje de los espacios en relación con el total de la página es del $27.5 \%$

8.7. Los principales hechos noticiosos están relacionados con acciones delictivas y accidentes: persecuciones, ejecuciones, secuestros o plagios, asesinatos en diversas formas (con arma blanca, pistolas), robos, asaltos, liberación de secuestrados por soldados del ejército, entre otros. En todos los casos, los hechos van acompañados siempre de violencia.

8.8. La violencia expresada en los hechos noticiosos publicados en los periódicos objeto de estudio, comprende todas sus tipificaciones; verbal, física, psicológica, familiar, social, colectiva. Ésta acompaña siempre a los hechos y está presente en las conductas de los participantes y agresores.

8.9. Los actores de los hechos son las víctimas (niños, personas civiles, obreros, profesionistas, estudiantes, albañiles, choferes, taxistas, empleados y los delincuentes. También policías ministeriales, peatones, agentes de tránsito, agentes del ministerio público, vecinos, integrantes de la Agencia Estatal de Investigación (A.E.I), entre otros.

8.10. El lenguaje empleado en los encabezados y en el cuerpo de las noticias de los tres periódicos en las 3 etapas es accesible para la generalidad de los lectores. Es coloquial, sin rebuscamientos y, en ocasiones, se emplean vocablos populares, como parte de la autorregulación lingüística, sin rayar en la vulgaridad sino con apego a los usos y costumbres.

8.11. En la redacción del cuerpo de las noticias analizadas se emplean abundantes y variados verbos que enfatizan las expresiones. En promedio de dos en los encabezados y hasta 10 en los mensajes de los discursos periodísticos. Asimismo, suficientes adjetivos sobre todo calificativos. Se ubicaron adverbios de varias clasificaciones. 
8.12. Los encabezados son de 5 a 8 palabras y una de ellas es un verbo, al cual lo acompañan sustantivos y adjetivos de gran carga lingüística. Quien utiliza más palabras en los encabezados es Milenio. El total de párrafos de cada noticia y periódico varía. En promedio son entre 10 y 12 párrafos, porque en el periódico El Norte éstos son muy cortos.

8.13. No hay diferencias significativas en los espacios ocupados por las noticias, ni por los espacios de las fotografías y su porcentaje en relación con el total. Se repiten los personajes principales. El lenguaje es casi el mismo en las tres etapas. Asimismo, se emplean en promedio las mismas cantidades de verbos, adjetivos y adverbios, con suficiente carga semántica

\section{Bibliografía}

AGUILLÓN VALE, P. (2010). "Construcción ideológica de la violencia delictiva en la prensa venezolana." Comunicación y Sociedad 13, .p.69-79. Informe. Web. 13 Junio 2011. http://www.comunicacionysociedad.cucsh.udg.mx/sites/default/ files/3_4.pdf [4-03-2012]

ARRIAGA, J. (2002). La nota roja: "Colombianización" o "mexicanización" periodística. Sala de prensa web para profesionales de la comunicación iberoamericana. Año IV, Vol. 2 .p. 50-60 http://www.saladeprensa.org/art375.htm [28-072012].

BARATA, F. (2010). Retos pendientes en el periodismo de nota roja. (Spanish). Chasqui (13901079), (110), P. 54-61. Retrieved from EBSCOhost.

CARRIÓN, F. (2008). Violencia y medios de comunicación: populismo mediático. (Spanish). URVIO - Revista Latinoamericana de Seguridad Ciudadana, (5) p. 7-12. http://flacsoandes.org/dspace/bitstream/10469/1501/3/RFLACSO-U05-01Carrion.pdf

CLAUSO, RAÚL. (2007) Cómo se construyen las noticias. Los secretos de las técnicas periodísticas. Buenos. Aires.: La Crujía.

ESQUIVEL HERNÁNDEZ, JOSÉ LUIS. (2009). Periodismo noticioso en diez lecciones. Monterrey: Universidad Autónoma de Nuevo León.

GORZ, M. y ULLOA, P. (1988). ABC del periodismo. México: Pax.

GUERRERO MARTINEZ, M. (2010). Los medios y los miedos. Nexos: Sociedad, Ciencia, Literatura .p.106-117. Informe. http://www.nexos.com.mx/?P=leerarticulo\&Article $=73134$ [27-07-2012]

LARA KLAHR M.; BARATA, F.; LÓPEZ PORTILLO VARGAS, E. (2010), Nota [N] Roja, la vibrante historia de un género y una nueva manera de informar. México: Debate: Randon House Mondadori.

LIPOVETZKY, G. (1987). El imperio de lo efímero: La moda y su destino en las sociedades modernas. Barcelona: Anagrama.

MACASSI, S. (2006). La prensa amarilla en América Latina., Ecuador: Red Revista Latinoamericana de Comunicación CHASQUI, P. 
RODRÍGUEZ, M. (2007) "Huellas del relato policial en México.” Anales de la Literatura Hispanoamericana .p.59-70.

RAGANMIM, F. (2007), 10(1) p. 9-24, [18-07-2012]. La actividad periodística entre la ley, la ética y la responsabilidad social. Un diagnóstico de las noticias asociadas al delito.

WARREN. Carl N. (1973). Géneros Periodísticos Informativos. México: Prisma.

\section{Los autores}

Dr. Sergio Manuel de la Fuente Valdez. Licenciado en Ciencias de la Comunicación. FCC de la UANL. Licenciatura y Maestría en Lengua y Literatura Españolas. Especialización y Maestría en Formación Docente (UPN), Doctorado en Comunicación Social, Facultad de Comunicación de Universidad de la Habana. Participó con ponencias en la Asociación Mexicana de Investigadores de la Comunicación (AMIC) (CONEICC), FELAFACS y RAIC. Escrito 8 artículos en extenso. Ha publicado el libro El Editorial y Artículo Editorial en Prensa Regiomontana: correspondencia teórico- práctica y coordinó el libro: Estudios de Comunicación, Medios y Educación. Profesor e investigador, titular A con perfil PROMEP.

M.E.S. Lucinda Sepúlveda García. Licenciada en Ciencias de la Comunicación Social, Universidad Regiomontana. Maestría en Enseñanza Superior, Facultad de Filosofía y Letras, UANL, 2003.Directora de la Facultad de Ciencias de la Comunicación de la UANL, subdirectora académica y de Estudios de Posgrado e Investigación de FCC. Ha participado en congresos, foros y encuentros a nivel nacional e internacional. Autora y coautora de libros: Guía para la selección de créditos, Plan 401". "Treinta y tres". FCC de la UANL. Miembro del Consejo de Participación Ciudadana 2013-2014 del Instituto Estatal de las Mujeres, 2013. Vicepresidenta de la región México de la Federación Latinoamericana de Facultades de Comunicación Social (FELAFACS). 